Disponível em

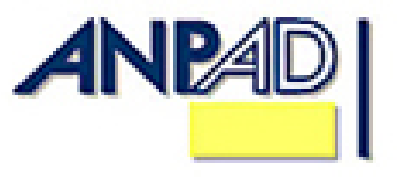

http://www.anpad.org.br/rac

RAC, Rio de Janeiro, v. 17, n. 6, art. 3, pp. 679-703, Nov./Dez. 2013

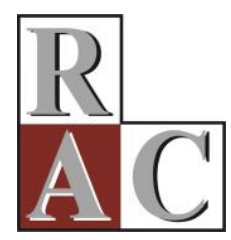

\title{
Internet Móvel nas Organizações: Fatores de Adoção e Impactos sobre o Desempenho
}

\section{Organizations' Use of Mobile Internet: Adoption Factors and Impacts on Performance}

Guilherme Lerch Lunardi

E-mail: gllunardi@furg.br

Universidade Federal do Rio Grande - FURG

FURG, Campus Carreiros, Av. Itália km 8, Rio Grande, RS, Brasil.

Décio Bittencourt Dolci

E-mail: dbdolci@gmail.com

Universidade Federal do Rio Grande - FURG

FURG, Campus Carreiros, Av. Itália km 8, Rio Grande, RS, Brasil.

Jonatas Wendland

E-mail: wendlandjonatas@yahoo.com.br Universidade Federal do Rio Grande - FURG

FURG, Campus Carreiros, Av. Itália km 8, Rio Grande, RS, Brasil. 


\title{
Resumo
}

Recentemente, destaca-se a integração da Internet e da telefonia móvel, culminando no surgimento de outra tecnologia, chamada Internet Móvel (IM). Embora venha despertando interesse entre executivos e acadêmicos, conhece-se pouco sobre a adoção dessa tecnologia nas organizações. Assim, objetivou-se neste estudo identificar os principais motivos que têm levado as organizações a adotar a IM, além de apurar os efeitos percebidos do uso dessa tecnologia no desempenho organizacional. O estudo se caracteriza como uma pesquisa quantitativa de caráter exploratório, realizada com 96 empresas localizadas no Rio Grande do Sul. Para tal, utilizou-se como base o modelo de adoção de TI proposto por Lunardi, Dolci e Maçada (2010). Os resultados obtidos sugerem que a adoção da Internet Móvel é influenciada por três distintos fatores: utilidade percebida, ambiente organizacional e pressões competitivas, sendo a utilidade percebida o principal motivador. No que se refere aos efeitos percebidos do uso da IM no desempenho organizacional, o estudo indica que a Internet Móvel aumenta principalmente a produtividade da empresa, sendo seguido pela obtenção de novos clientes, pelo aumento das receitas e, por fim, pela redução dos custos operacionais.

Palavras-chave: internet móvel; adoção; impacto de TI; desempenho organizacional.

\begin{abstract}
Recently, the integration of Internet and mobile technologies has been a worldwide phenomenon, culminating in the emergence of another technology called Mobile Internet (MI). Although this has received interest from executives and academics, there is little known about the adoption of this technology in organizations. Thus, we aimed to identify the main reasons that organizations adopt MI and analyze the perceived effects of MI use on organizational performance. The study was characterized as an exploratory quantitative research conducted with 96 firms from Rio Grande do Sul state in Brazil. We used the IT adoption model proposed by Lunardi, Dolci and Maçada (2010) as the main foundation. Results suggest MI adoption is influenced by three distinct factors: perceived usefulness, organizational readiness and competitive pressures, whereby perceived usefulness is the primary motivator. Regarding the perceived effects of MI use on organizational performance, we found that MI primarily increases productivity, but also attracts new customers, increases sales and reduces operating costs.
\end{abstract}

Key words: mobile internet; adoption; IT impact; organizational performance. 


\section{Introdução}

A Internet e a telefonia móvel despontam concomitantemente pelo crescimento que têm alcançado nos últimos anos, tanto no Brasil como em outros países. Mais recentemente, destaca-se a integração dessas tecnologias, originando a Internet Móvel (IM). Usada em conjunto com outra tendência, a dos artefatos computacionais portáveis - como notebook, palmtop, smartphone e tablet -, é possível atingir níveis de conectividade com mobilidade nunca antes experimentados, o que vem despertando interesse nos meios acadêmico e empresarial. No entanto, a maior parte dos estudos publicados direciona-se ao entendimento do consumidor individual, conhecendo-se pouco sobre a adoção da Internet Móvel nas empresas. Nesse sentido, pode-se afirmar que o uso da IM nas organizações, embora crescente, ainda está em seu estágio inicial em termos de conhecimento científico (San Martín, López-Catalán, \& Ramón-Jerónimo, 2012; Zhang, Zhu, \& Liu, 2012). Exploram-se questões relacionadas a esse tema neste artigo.

O Brasil atingiu 75 milhões (quase $40 \%$ da população) de usuários da Internet em 2012, estando em quinto lugar entre os 20 países com maior número de pessoas conectadas na rede mundial de computadores, atrás apenas de Japão, Índia, Estados Unidos e China (Info, 2012). Igualmente acentuada é a evolução da telefonia móvel no Brasil, que ultrapassou 250 milhões de linhas ativas em 2012 (Agência Nacional de Telecomunicações [Anatel], 2012). Diante deste cenário, fazem-se necessários vultosos investimentos na infraestrutura da Internet Móvel no Brasil. Nesse sentido, o Ministério das Comunicações informou medidas para a desoneração de equipamentos e obras civis para redes de banda larga prevista no plano Brasil Maior, esperando antecipar cerca de R $\$ 18$ bilhões em investimentos das empresas de telecomunicações, a serem feitos até 2016 (Amato, 2012).

O investimento em banda larga móvel parece essencial no Brasil, visto que há muitos locais sem estrutura fixa para acesso à Internet. Thompson e Garbacz (2011) revelam importante impacto positivo da banda larga móvel no Produto Interno Bruto (PIB) dos países, sendo os benefícios mais significativos em países de baixa renda e áreas rurais. Similarmente, observando microrregiões, Kolko (2012) e Bojnec e Ferto (2012) demonstram a associação entre expansão de banda larga e crescimento econômico.

No que se refere à popularização dos artefatos computacionais portáveis, é válido salientar que a aquisição de notebooks em 2011 ficou praticamente estável no mundo todo, enquanto a posse de desktops apresentou queda neste período. Com relação aos tablets, ainda que possam ser considerados entrantes nesse mercado, a previsão é que eles o dominem em quatro anos (Idgnow, 2012). Em termos de smartphones, $32 \%$ dos consumidores mundiais tinham a intenção de comprar esse aparelho em 2012 , enquanto apenas $24 \%$ queriam um celular comum. No Brasil, as vendas de smartphones atingiram os 16 milhões de unidades em 2012, número 78\% maior do que as vendas em 2011, enquanto os celulares comuns apresentaram uma queda nas vendas de 25\% (Idgnow, 2013).

Na Academia, é a partir de 2007 que o termo Internet Móvel recebe destaque. A título de ilustração, na Figura 1, apresenta-se a evolução do número de citações presentes na base de dados Social Sciences Citation Index (SSCI) a artigos contendo mobile internet no título; consulta realizada em 10 de abril de 2012. Tal evolução confirma o observado por Saccol e Reinhard (2007), que as tecnologias de informação móveis, sem fio e ubíquas figuravam entre os principais temas emergentes discutidos na área de Sistemas de Informação (SI). 


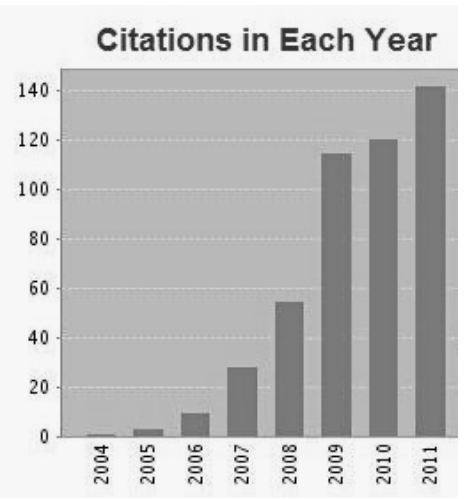

Figura 1. Evolução de Artigos Científicos sobre Internet Móvel.

Muitos pesquisadores têm se esforçado para investigar os mais diversos serviços envolvendo essas tecnologias, como os serviços financeiros móveis (Hsu, Wang, \& Lin, 2011), as transações móveis (Khalifa \& Shen, 2008) e o comércio móvel (Zhang et al., 2012). No entanto, a maior parte dos estudos ainda é de cunho técnico ou para o entendimento do comportamento do consumidor (San Martín et al., 2012), não adotando o ponto de vista das empresas. Poucos estudos, como Balloco, Mogre e Toletti (2009) e San Martín, López-Catalán e Ramón-Jerónimo (2012), examinam esse fenômeno enfatizando a Internet Móvel sob a perspectiva da empresa. O desenvolvimento de estudos sobre adoção e difusão de diferentes TIs no meio empresarial pode fornecer um conjunto bastante rico de resultados e, inclusive, teorias que possam ser aplicadas diretamente para compreender melhor o impacto de sua utilização, identificando também fatores relacionados ao sucesso e ao fracasso de sua implantação (Lunardi, Dolci, \& Maçada, 2010). Além disso, as pesquisas sobre a adoção e o uso da TI têm sido motivadas pelo desejo de predizer fatores que podem levar de forma bem sucedida tais aplicações (Rose \& Straub, 1998). No entanto, observando-se o estágio em que se encontram as pesquisas sobre Internet Móvel nas organizações, fica evidenciada a necessidade de estudos de caráter exploratório.

O rápido crescimento da IM tem trazido implicações significativas na forma como as organizações podem fazer seus negócios (Corso, Cavedon, \& Freitas, 2011; San Martín et al., 2012). Novas interfaces e formatos, como o iPhone, da Apple, e os MID (Mobile Internet Device), estão potencializando o consumo desses equipamentos e a competição entre as empresas na busca de novas possibilidades móveis. Essa nova configuração não representa somente uma facilidade de conexão, mas toda uma potencialidade de novos usos, bem como a transformação dos existentes (Pellanda, 2009). No entanto, não se pode simplesmente transferir as regras da Internet fixa para a Internet Móvel, especialmente porque a Internet Móvel difere significativamente em vários aspectos da Internet fixa (Chae \& Kim, 2003).

A partir destas considerações iniciais, demonstrando-se lacunas no conhecimento sobre o fenômeno Internet Móvel nas organizações, levanta-se a seguinte questão: Quais são as causas, aplicações e consequências da adoção da IM nas organizações e as possíveis relações entre as variáveis dessas dimensões? Assim, apresentam-se como objetivos desta pesquisa explorar: (a) os principais motivos que têm levado as organizações a adotar a IM; (b) o uso da IM nas organizações; (c) os efeitos percebidos do uso desta tecnologia no desempenho organizacional; e (d) possíveis associações entre fatores de adoção, aplicações e desempenho organizacional no contexto da Internet Móvel.

\section{Referencial Teórico}

Nesta seção, primeiramente, expõe-se o contexto teórico sobre IM, apresentando-se conceitos sobre o tema, uma revisão dos principais trabalhos realizados no Brasil e aspectos sociotécnicos que 
impulsionam o negócio Internet Móvel. A seguir, apresentam-se estudos que serviram de base à investigação das duas dimensões apresentadas neste artigo: fatores que influenciam a adoção e desempenho organizacional após a adoção da TI.

\section{Internet móvel}

Recentes evoluções nas tecnologias de informação e comunicação proporcionaram que computadores e outros dispositivos acessem a Internet sem a necessidade de fios para a conexão e a realização de serviços por ela disponibilizados, como e-mail, mensagens instantâneas, newsgroups, telnet, FTP e World Wide Web (Laudon \& Laudon, 2010). Deste avanço tecnológico, emergiu o termo Internet Móvel (do inglês Mobile Internet), sendo usado tanto academicamente como comercialmente. Refere-se ao acesso em tempo real à Internet a partir de dispositivos móveis sem fio. Os dispositivos móveis podem ser PDAs, telefones celulares ou computadores que possuam algum dispositivo integrado ou independente, como um modem USB ou uma placa PCMCIA. Sobretudo, este modo de acesso é importante em lugares que não dispõem de infraestrutura de cabeamento.

A adoção da IM tornou-se mais acentuada a partir da tecnologia celular de terceira geração, disponibilizada no Brasil em 2007 (Chaves, Veríssimo, Silva, Souza, \& Cotti, 2010). Por ser uma tecnologia relativamente recente no mercado brasileiro, ainda é escassa a publicação de artigos científicos usando essa terminologia até o presente momento no país. Assim sendo, para a realização de um quadro teórico, torna-se necessário também recorrer a estudos que fazem uso de outros termos conexos à IM - como tecnologias móveis, tecnologia móvel e sem fio (TIMS), mobilidade, $m$-business e mobile business - observando a presença da tecnologia celular para acesso à Internet.

Saccol e Reinhard (2007) apresentam um mapeamento do estado-da-arte da pesquisa sobre as tecnologias de informação móveis, sem fio e ubíquas em Administração, contendo definições para uma boa parte dos conceitos relacionados ao tema. Mostram que Tecnologia Móvel (Mobile) caracteriza-se pela portabilidade, capacidade de se levar um dispositivo para qualquer lugar, e que Tecnologia Sem Fio (wireless) distingue-se pela possibilidade de conectarem-se a outros equipamentos por links de comunicação sem o uso de fio. Da fusão dessas duas tecnologias, têm-se as Tecnologias Móveis e Sem Fio (TIMS) (Corso et al., 2011; Saccol \& Reinhard, 2005). No mesmo estudo, Saccol e Reinhard (2007), ao examinarem a produção científica brasileira no período entre 1997 e 2004, revelam uma produção incipiente sobre este tema. Não encontraram qualquer estudo versando sobre o tema em veículos de publicação acadêmica conceituados em nível A pela Capes na área de Administração, havendo apenas uma pequena quantidade de artigos publicados em congressos científicos (quatro em Anais do EnANPAD e um no ENEGEP).

Atualmente, já é possível perceber certo aumento nesta produção, principalmente nos últimos três anos. Consultando-se o site da ANPAD em setembro de 2013, identificou-se a presença de 32 artigos, publicados entre 2005 e 2013 (período posterior ao levantamento realizado por Saccol e Reinhard, 2007), tratando de questões relacionadas a tecnologias móveis e sem fio. Cabe ressaltar que, destes artigos, 20 foram publicados entre 2011 e 2013 (cinco em 2011, cinco em 2012 e dez em 2013), e que grande parte já referia a capacidade de acesso à Internet através de dispositivos móveis baseados em tecnologia celular. Os artigos estão publicados em Anais de diferentes eventos organizados pela ANPAD - EnANPAD, EnADI, EMA, EnAPG e EnGPR - apresentando estudos com diferentes enfoques.

Considerando as pesquisas em nível organizacional, encontram-se: (a) trabalhos teóricos, como o de Machado e Freitas (2007), propondo um modelo para o planejamento das iniciativas de adoção de tecnologias móveis pelas organizações na interação com seus públicos-alvo; e o de Bento, Martens e Freitas (2013), apresentando um conjunto de elementos decorrentes da adoção de tecnologias móveis em equipes de vendas; (b) estudos de caso, como o de Saccol e Reinhard (2005), Manica e Saccol (2009), Costa, Saccol e Vieira (2011), visando analisar aplicações de TIMS e decorrências de suas utilizações; e Gonçalves e Joia (2011), analisando os efeitos do uso das tecnologias móveis em profissionais usuários de smartphones; (c) surveys, como a de Tavares et al. (2012), testando um 
modelo estrutural para mostrar a influência das tecnologias móveis na inovação em serviços; e Cavazotte, Brollo e Moreno (2009), analisando os efeitos do uso das tecnologias móveis em profissionais usuários de telefones celulares inteligentes; e (d) estudos utilizando dados secundários, como o de Cappellozza, Sanchez e Albertin (2011), investigando a relação entre infraestrutura de TI e dispositivos móveis; e Klein, Karl e Cunha (2013), pesquisando o conceito de capacidade organizacional para a mobilidade. Ainda que boa parte desses estudos não utilize explicitamente o termo IM, percebe-se o seu uso nas organizações.

Considera-se o termo IM como o mais adequado para a presente pesquisa, pois focaliza o uso dos serviços da Internet através de dispositivos móveis. Embora, fisicamente, sejam artefatos tecnológicos distintos - Internet e Dispositivo móvel sem fio -, sob a ótica da tecnologia em uso (Orlikowski, 2000) eles fundem-se, precisando ser avaliados conjuntamente. Orlikowski (2000) chama atenção para a necessidade de se distinguir as propriedades da tecnologia em uso da tecnologia per se, cunhando o termo tecnologia na prática. Conforme a autora, as observações da tecnologia na prática são as mais valiosas para os estudos organizacionais, pois do uso repetitivo de uma tecnologia é que as propriedades tecnológicas se tornam constituídas.

Conforme Turban, Leidner, McLean e Wetherbe (2010), diversos fatores sociotécnicos impulsionam a rápida expansão da utilização dos dispositivos móveis sem fio para acesso à Internet, a saber: (a) a disseminação - o número de celulares cresce exponencialmente em todo o mundo, sendo cada vez mais comum a capacidade de acesso à Internet por meio desses dispositivos; (b) a popularização - o uso do celular e de outros dispositivos móveis sem fio é um fenômeno social, principalmente na faixa etária entre 15 e 25 anos de idade; (c) o barateamento - o preço dos dispositivos móveis está mais acessível aos compradores, em grande parte devido à redução de custos propiciada pela escala de produção; (d) a funcionalidade - a introdução de novos recursos nos dispositivos, como também de aplicativos na Internet, o que torna o conjunto cada vez mais útil; e (e) a velocidade de transmissão de dados - a largura de banda atual propicia realizar operações que antes só eram possíveis usando computadores conectados à Internet via fio.

As características da IM podem ser entendidas a partir de três perspectivas diferentes: a do usuário, a do ambiente e a do sistema (Chae \& Kim, 2003). Do ponto de vista do usuário, dispositivos de Internet Móvel são geralmente mais pessoais e individuais do que os dispositivos de Internet fixa. Não é incomum que as pessoas compartilhem seus computadores desktop, mas é muito raro que aconteça compartilhamento com telefones que contenham Internet Móvel. Portanto, o dispositivo móvel sempre carrega sua identidade de usuário. Em segundo lugar, do ponto de vista do ambiente, sistemas de Internet Móvel geralmente oferecem conexão instantânea com a Internet, o que permite aos usuários o acesso à rede em qualquer lugar e a qualquer hora. Um sistema de Internet Móvel é portátil e está sempre, ou quase sempre, disponível. Por outro lado, sistemas de Internet fixa normalmente não são móveis e exigem longos processos de espera, tais como a inicialização do computador, que normalmente leva mais do que alguns minutos. Em terceiro lugar, do ponto de vista do sistema, a maioria dos sistemas de Internet Móvel, especialmente os telefones celulares, tem um menor nível de recursos disponíveis em relação às fornecidas pela Internet fixa. Embora os dispositivos de Internet Móvel sejam mais portáteis e acessíveis, eles têm telas menores e menos convenientes quanto aos dispositivos de entrada e saída, e possuem menor capacidade de processamento multimídia do que os computadores desktop, por exemplo.

Segundo Kim, Chan e Gupta (2007), os serviços oferecidos pela Internet Móvel podem ser classificados em: comércio, comunicação e conteúdo. Comércio varia do banco móvel ao ticket eletrônico para a compra de produtos físicos, enquanto o e-mail e os serviços interativos, como batepapo, são considerados serviços de comunicação. Conteúdo inclui downloads, notícias, atualizações do trânsito ou das bolsas de valores, bem como de outros serviços sensíveis ao tempo ou baseados na localização. Uma outra classificação encontra-se em Reuver, Ongena e Bouwman (2013). Os autores separam os aplicativos em: entretenimento (por exemplo, downloads de jogos e músicas), básicos (email, navegação na web, mecanismos de busca) e transacionais (reserva ou compra de serviços e de produtos). 
Neste cenário tecnológico, os gestores buscam vantagens competitivas para as suas organizações por meio de aplicações inovadoras que fazem uso da IM, como por exemplo: suporte à equipe de vendas, gerenciamento de equipes móveis, rastreamento de frotas, monitoramento de dispositivos de segurança, entre outras aplicações relacionadas ao tipo de negócio (Bento, Martens, \& Freitas, 2013; Saccol \& Reinhard, 2007; Sandi \& Saccol, 2010). Outros serviços da Internet, populares no acesso tradicional com fio, também são possíveis de se utilizar através da IM, como enviar e receber e-mails, acessar as redes sociais, os bancos e utilizar softwares de comunicação, como MSN, por exemplo (Turban, Leidner, McLean, \& Wetherbe, 2010).

A partir da utilização dessas aplicações, espera-se que as empresas obtenham diferentes benefícios organizacionais (Balloco, Mogre, \& Toletti, 2009; Machado \& Freitas, 2007; San Martín et al., 2012). Como acontece com qualquer inovação que rapidamente altera a forma como as pessoas executam suas atividades, o crescimento da IM tem provocado discussões acerca de seus benefícios e desvantagens, assim como tem ocorrido em relação a outras tecnologias de uso regular, como a Internet e demais artefatos tecnológicos (Gonçalves \& Joia, 2011). As tecnologias móveis permitem aos usuários acesso a informações e a aplicativos, a qualquer hora e local. Isso proporciona maior flexibilidade na comunicação, na colaboração e no compartilhamento de informação (Chen \& Nath, 2008). Esses ambientes facilitam o acesso aos sistemas corporativos e a ferramentas de produtividade, tais como e-mail e agendas eletrônicas (Ghose \& Han, 2011; Gonçalves \& Joia, 2011). As organizações que fazem uso dessas tecnologias não apenas fornecem aos seus trabalhadores capacidades de computação nômade, mas também reprojetam seus processos de negócio, procedimentos operacionais, estrutura organizacional e sistemas de recompensa em torno das necessidades emergentes de novos modelos de gestão (Chen \& Nath, 2008), o que pode resultar na melhoria gradual das práticas de trabalho, permitindo ganhos de eficiência e flexibilidade.

\section{Fatores que influenciam a adoção da Internet Móvel e o impacto do seu uso no desempenho organizacional}

Pesquisas na área de SI revelam que inúmeros fatores influenciam a adoção da TI, podendo inclusive mudar em função do tipo de tecnologia e do contexto onde ela está inserida (Kim, Chan, \& Gupta, 2007). Um dos primeiros modelos estatísticos sobre adoção de tecnologia da informação, o TAM (Technology Adoption Model) (Davis, 1989), demonstrou que, entre tantas variáveis já percebidas na época, duas eram extremamente determinantes: a utilidade e a facilidade de utilização. Primeiro, pessoas tendem a usar ou não uma tecnologia na medida em que elas acreditam que esta vai ajudá-las a executar melhor seu trabalho. Segundo, mesmo percebendo a utilidade da tecnologia, seu uso será influenciado pela facilidade de utilização.

Modelos como o TAM, normalmente, são adequados para estudos em um contexto organizacional, no qual são distintos o consumidor do serviço (empresa) e o usuário da tecnologia. No entanto, o contexto pode ser um tanto diferente ao investigar o uso da IM nas empresas, uma vez que apresenta a particularidade de, além de servir aos propósitos organizacionais, também poder ser usada para fins pessoais (Kim et al., 2007). Assim, em muitos casos, os funcionários assumem o duplo papel de usuários da tecnologia e de consumidores do serviço. Considerando que há investimentos e despesas para se usar a tecnologia, é lógico pensar que a adoção pode variar em função de quem arca com as despesas, empresa ou usuário. Outro aspecto a ser considerado é que várias tecnologias implantadas nas empresas são mandatárias, ou seja, os funcionários são obrigados a usar. Nesse caso, o uso da tecnologia para o usuário pode ser percebido como um sacrifício.

Os paradoxos da tecnologia móvel (Corso, Freitas, \& Behr, 2012; Gonçalves \& Joia, 2011; Jarvenpaa \& Lang, 2005) emergem no processo de ação e experiência dessa tecnologia a partir da perspectiva do usuário, levando-se em consideração que tais ações e experiências são dependentes de fatores situacionais e contextuais. Isto é, os contextos social, organizacional, tecnológico e cultural influenciam as motivações e objetivos do indivíduo para usar uma tecnologia móvel. Nesse sentido, as decisões para usar a tecnologia móvel em distintas situações para diferentes propósitos, como 
comunicação, coordenação, eficiência, mobilidade e socialização, acabam por afetar, reforçar ou modificar aqueles contextos.

A fim de explicar a adoção da IM, observando-se mais minuciosamente este novo contexto, Kim et al. (2007) desenvolveram o VAM (Value-based Adoption Model). Neste modelo, o valor percebido da IM é resultante da percepção de dois benefícios (utilidade e prazer) e de dois estorvos (valor financeiro pago e tecnicidade). De fato, parece que tanto o valor financeiro como o prazer são questões importantes quando os consumidores adotam os serviços móveis voluntariamente também para fins pessoais. Em tecnicidade, encontram-se as questões associadas à facilidade de uso, apontadas anteriormente pelo TAM.

É válido observar que se encontra um conjunto de artigos direcionados a publicar investigações sobre a Internet Móvel com base nos modelos TAM e VAM (Hong, Thong, \& Tam, 2006; Kim et al., 2007; Souza, Ferreira, Hor-Meyll, Silva, \& Giovannini, 2012); no entanto, esses modelos não atentam para fatores ambientais e organizacionais da empresa. Ao buscar modelos que incluíssem esses fatores, encontrou-se o modelo de Lunardi, Dolci e Maçada (2010), que ainda não havia sido explorado no contexto da IM.

Lunardi, Dolci et al. (2010) assinalam que outros fatores importantes, como necessidade interna (Prates \& Ospina, 2004), ambiente organizacional (Cragg \& King, 1993) e pressões externas (Cragg \& King, 1993; Grandon \& Pearson, 2004), reunidos à utilidade percebida (Davis, 1989; Grandon \& Pearson, 2004), têm levado as organizações a adotarem diferentes TIs, apresentando as seguintes definições: Necessidade interna - quando a empresa adota a tecnologia em função de seu crescimento ou para melhor atender suas necessidades, garantindo, dessa forma, seu bom funcionamento; Ambiente organizacional - quando a empresa adota a tecnologia porque percebeu que possuía um ambiente favorável à sua utilização, com funcionários em condições de utilizá-la e com uma estrutura organizacional adequada; Pressões Externas - quando a empresa adota a tecnologia em função da grande concorrência existente, porque os concorrentes diretos têm adotado ou ainda por influência de clientes, fornecedores ou do próprio governo; e Utilidade Percebida - quando a empresa adota a tecnologia porque percebeu que seria útil no seu dia a dia, melhorando a realização de tarefas e suas atividades, aumentando a segurança, o controle e o atendimento aos clientes.

Nesse sentido, diferentes motivos influenciam a decisão de investir e, não obstante, a forma com que esses investimentos serão realizados, o que consequentemente afetará os resultados esperados a partir da utilização da tecnologia adotada. Ao perceber o fenômeno desta forma, Lunardi, Dolci et al. (2010) propõem um modelo (Figura 2) mostrando a influência dos fatores da adoção no desempenho organizacional, ainda que esta influência seja mediada pelo planejamento dos investimentos em TI. A partir do modelo de Lunardi, Dolci et al. (2010), percebendo-se que ele ainda não havia sido usado no contexto da Internet Móvel, exploraram-se os mesmos fatores de adoção e as possíveis consequências do uso dessa tecnologia no desempenho organizacional. No entanto, é válido observar a necessidade de se verificar a adequação dos fatores de adoção propostos no modelo ao contexto da Internet Móvel; assim, a exemplo de Lunardi, Dolci et al. (2010), aplica-se uma análise fatorial exploratória (AFE), cujo objetivo é obter dimensões latentes, descrevendo, assim, os dados em um número bem menor de conceitos (Hair, Anderson, Tatham, \& Black, 2005). 


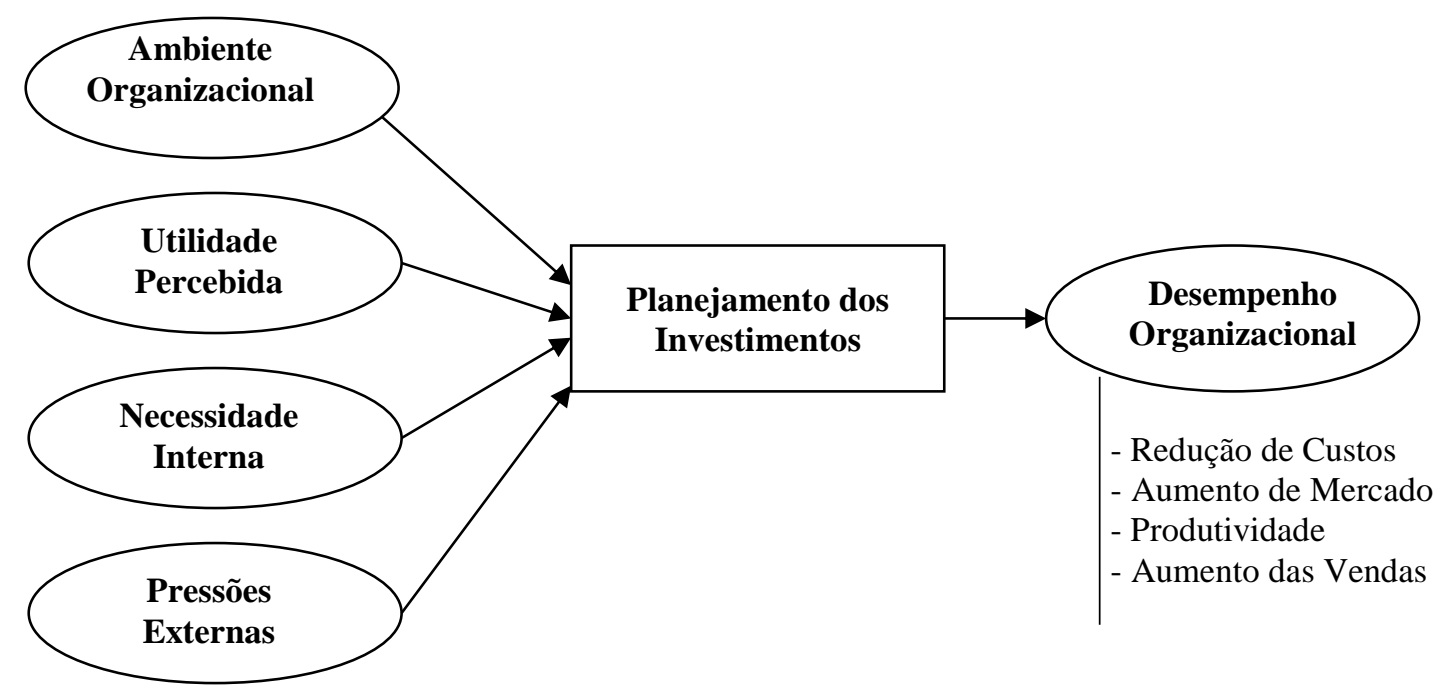

Figura 2. Modelo Teórico.

Fonte: Lunardi, G., Dolci, P., \& Maçada, A. (2010). Adoção de tecnologia de informação e seu impacto no desempenho organizacional: um estudo realizado com micro e pequenas empresas. Revista de Administração, 45(1) 5-17.

No que se refere às consequências do efetivo uso da IM, especula-se que esta TI pode proporcionar uma série de ganhos às empresas, como o aumento da produtividade, maiores vendas, redução de custos operacionais, aumento da base de clientes, decisões com maior qualidade, além da diferenciação de produtos e serviços inovadores (Hu \& Plant, 2001; Machado \& Freitas, 2007). Esses benefícios, quando ocorrem, afetam o desempenho organizacional, estando diretamente associados à melhoria da eficiência das operações dentro de processos específicos da organização (Melville, Kraemer, \& Gurbaxani, 2004).

\section{Metodologia}

O estudo caracteriza-se como uma pesquisa quantitativa de caráter exploratório (em um primeiro momento), e descritivo e correlacional (em um segundo), realizada com 96 empresas localizadas no Rio Grande do Sul. A pesquisa desenvolveu-se entre outubro de 2010 e abril de 2011, e envolveu procedimentos de coleta, validação e análise de dados. Como forma de investigar a adoção da IM sob a ótica das empresas (observando-se diferentes fatores que conduzem-nas a essa adoção), utilizou-se o instrumento desenvolvido por Lunardi, Dolci et al. (2010), que identificaram os construtos Utilidade Percebida, Necessidade Interna, Ambiente Organizacional e Pressões Externas como os principais motivos que levaram as micro e pequenas empresas a adotar TI. Da mesma forma, tomou-se por base o referido estudo para mensurar os impactos do uso da Internet Móvel no desempenho organizacional, através das seguintes medidas de análise: Redução de Custos, Aumento das Vendas, Aumento da Produtividade e Aumento do Mercado.

O questionário dividiu-se em quatro seções: (a) informações gerais: contendo seis questões de caracterização da amostra (como setor de atuação, ano de fundação, número de funcionários, tipo de dispositivo móvel utilizado, percentual de funcionários que utiliza a IM e o ano em que passou a utilizá-la); (b) principais aplicações da IM na empresa (contendo uma lista de 11 aplicações corporativas, operacionalizadas em uma escala Likert de 5 pontos -variando de nunca utiliza a utiliza todo o tempo); (c) motivos de adoção da IM (contendo 16 questões fechadas e operacionalizadas em uma escala Likert de 5 pontos - variando de discordo totalmente a concordo totalmente); e (d) impacto da IM no desempenho organizacional (contendo 4 questões fechadas e operacionalizadas em uma escala Likert de 5 pontos - variando de discordo totalmente a concordo totalmente). $\mathrm{O}$ questionário foi enviado por e-mail a uma base de dados contendo 326 clientes corporativos de uma empresa de telefonia móvel localizada na região sul do Rio Grande do Sul. O e-mail detalhava a 
pesquisa e solicitava que o questionário anexado fosse respondido pelo responsável de TI na empresa. Ao final do período de coleta, retornaram 96 questionários válidos. A caracterização da amostra pode ser visualizada na Tabela 1.

A amostra é composta predominantemente por empresas industriais $(38,5 \%)$ e de serviços $(40,6 \%)$, sendo as micro $(43,8 \%)$ e pequenas empresas $(21,9 \%)$ as mais comuns. Quanto aos dispositivos móveis utilizados, o pen modem $(87,5 \%)$ e o smartphone (50\%) são os preferidos. Mais da metade das empresas investigadas possui entre 10 e $20 \%$ dos seus funcionários com acesso à Internet Móvel.

Tabela 1

Caracterização da Amostra

\section{Característica}

\section{n}

$\%$

Tipo de Empresa

Indústria

Comércio

Serviços

40,6

Agropecuária

3

3,1

Porte

Micro

42

43,8

Pequena

21

21,9

Média

Grande

Não informado

Ano de Fundação

Antes de 1991

De 1991 a 2000

Depois de 2000

Não informado

\section{Tecnologias Utilizadas}

Pen Modem

Smartphone/PDA

Celular comum

\section{Usuários de Internet Móvel na Empresa}

Entre 10 e $20 \%$

49

51,0

De 20 a $50 \%$

Mais de $50 \%$

Não informado 1

Total 96 100,00

Após a coleta de dados e a purificação dos questionários, realizaram-se os testes Shapiro-Wilk e Kolmogorov-Smirnov para verificar a normalidade das variáveis e aplicaram-se dois testes estatísticos para explorar as variáveis - latentes e observáveis - do instrumento proposto: a análise fatorial e o alfa 
de Cronbach. Na sequência, procedeu-se a parte descritiva e correlacional da pesquisa. Conforme Barbetta (1998), a análise com base em correlações é usualmente feita em termos exploratórios, sendo um passo intermediário na análise de um problema. A seguir, apresentam-se os resultados encontrados no estudo.

\section{Resultados}

No contexto da Internet Móvel, a aplicação da análise fatorial (com rotação Oblimin) (Tabela 2) não confirmou os quatro fatores inicialmente propostos na pesquisa, especialmente, devido aos critérios de associação entre as variáveis e ao grau de subjetividade das questões não apresentarem coerência conceitual, o que exigiu, inclusive, a eliminação de duas questões. Após este descarte, os constructos foram se tornando mais claros, definindo-se como solução de extração a formação com apenas três fatores, utilizando-se a divisão de componentes do terceiro constructo com autovalor igual a 0,895 . Conceitualmente, o principal critério para definir o número de constructos a serem extraídos é considerar apenas aqueles que apresentam autovalores maiores que 1 , uma vez que cada variável contribui com um valor 1 do autovalor total. Assim, qualquer fator individual deveria explicar a variância de pelo menos uma variável, se o mesmo fosse mantido para a interpretação. Entretanto, na prática, a maioria dos pesquisadores raramente usa um único critério para determinar quantos fatores devem ser extraídos; a seleção do número de constructos deve considerar também a estrutura conceitual da pesquisa e sua interpretação (Hair et al., 2005). O que se percebeu é que os constructos Pressões Externas e Necessidade Interna se agruparam em um mesmo fator, formando o constructo Pressões Competitivas.

Tabela 2

Análise Fatorial (Rotação Oblimin)

\section{Indicadores}

\section{Bloco}

F1

F2

Pressões Competitivas

$\mathrm{m} 2$. Por causa da grande concorrência existente.

$\begin{array}{rr}, 834 & , 867 \\ , 722 & , 840 \\ , 776 & , 803 \\ , 835 & , 776 \\ , 766 & , 606 \\ , 795 & , 538\end{array}$

m6. Por influência dos clientes, fornecedores e/ou governo.

m14. Porque os concorrentes também têm adotado.

m1. Manter-se atualizada tecnologicamente.

606

m15. Para realizar suas atividades com maior segurança.

\section{Utilidade Percebida}

m10. Atender melhor as suas necessidades.

m9. O seu negócio exigia.

m3. Realizar tarefas específicas mais rapidamente.

m11. Aumentar a sua competitividade.

\section{Ambiente Organizacional}

m8. Possuía funcionários com condições de utilizá-la.

m16. Possuía um ambiente favorável à sua utilização. 
Tabela 2 (continuação)

\begin{tabular}{lcccc}
\multicolumn{1}{c}{ Indicadores } & Bloco & F1 & F2 & F3 \\
\hline Initial eigenvalue & & 6,49 & 1,53 &, 895 \\
Porcentagem da variância explicada - rotated $(63,7 \%)$ & & $46,4 \%$ & $10,9 \%$ & $6,4 \%$ \\
Alfa de Cronbach $(0,91)$ & & 0,88 & 0,84 & 0,79 \\
KMO medida de adequação da amostra $(\mathrm{KMO}=0,90)$ & & & \\
Teste de Bartlet: qui-quadrado $=625,679$ & & & \\
\hline
\end{tabular}

Tornatzky e Fleischer (como citado em San Martín et al., 2012), ao desenvolverem um modelo genérico para adoção de novas tecnologias, sugerem três fatores-chave que influenciam essa adoção: o contexto tecnológico (definido pela competência tecnológica da organização), o contexto organizacional (que abrange fatores como: adequação, tamanho ou formalização) e o contexto ambiental (impactado por diferentes pressões competitivas). Nesse sentido, percebe-se que as pressões competitivas existentes no contexto ambiental atuam como mais um fator que incentiva o crescimento e a disseminação da IM (Shankar, Venkatesh, Hofacker, \& Naik, 2010). As empresas estão constantemente sofrendo pressões externas, tais como: concorrência, mudança da necessidade dos clientes, regulações governamentais e surgimento de novas tecnologias (Ungan, 2004). As pressões externas dos concorrentes, por exemplo, podem levar uma empresa a adotar uma inovação mesmo quando ela não percebe muitas vantagens nesta tecnologia. Diferentes pressões competitivas podem influenciar uma empresa a adaptar suas estratégias a uma nova situação (Grant, 2003), particularmente em setores nos quais existem grande rivalidade e incerteza quanto ao que os concorrentes estão fazendo (Pavlou \& El Sawy, 2010). Em estudo realizado sobre a adoção organizacional da tecnologia de radiofrequência (RFID), Wang, Wang, e Yang (2010) identificaram que empresas que adotaram RFID percebiam maiores pressões competitivas do que aquelas empresas que não a possuíam. Como tentativa de enfrentar essas pressões, as organizações procuram adotar a melhor situação possível (Ungan, 2004), ainda que em muitos casos não tenham certeza sobre o impacto que a solução adotada terá.

Quanto à fidedignidade das dimensões do instrumento, esta foi testada através do cálculo do alfa de Cronbach. O instrumento apresentou valor igual a 0,91, enquanto os coeficientes dos fatores situaram-se entre 0,79 e 0,88 , apontando boa consistência interna das medidas para estudos de natureza exploratória. A definição conceitual dos construtos resultantes visando a medir fatores de adoção no contexto da IM pode ser assim expressa: Utilidade Percebida - quando a empresa adota a IM porque percebeu que seria útil no seu dia a dia, melhorando a realização de tarefas e suas atividades; Ambiente Organizacional - quando a empresa adota a IM porque percebeu que possuía um ambiente favorável à sua utilização, com funcionários em condições de utilizá-la e com uma estrutura organizacional adequada; e Pressões Competitivas - quando a empresa adota a IM para responder as pressões externas advindas do mercado, da concorrência, de fornecedores, do governo e da própria inovação tecnológica. A Figura 3 apresenta o modelo ajustado da pesquisa. 


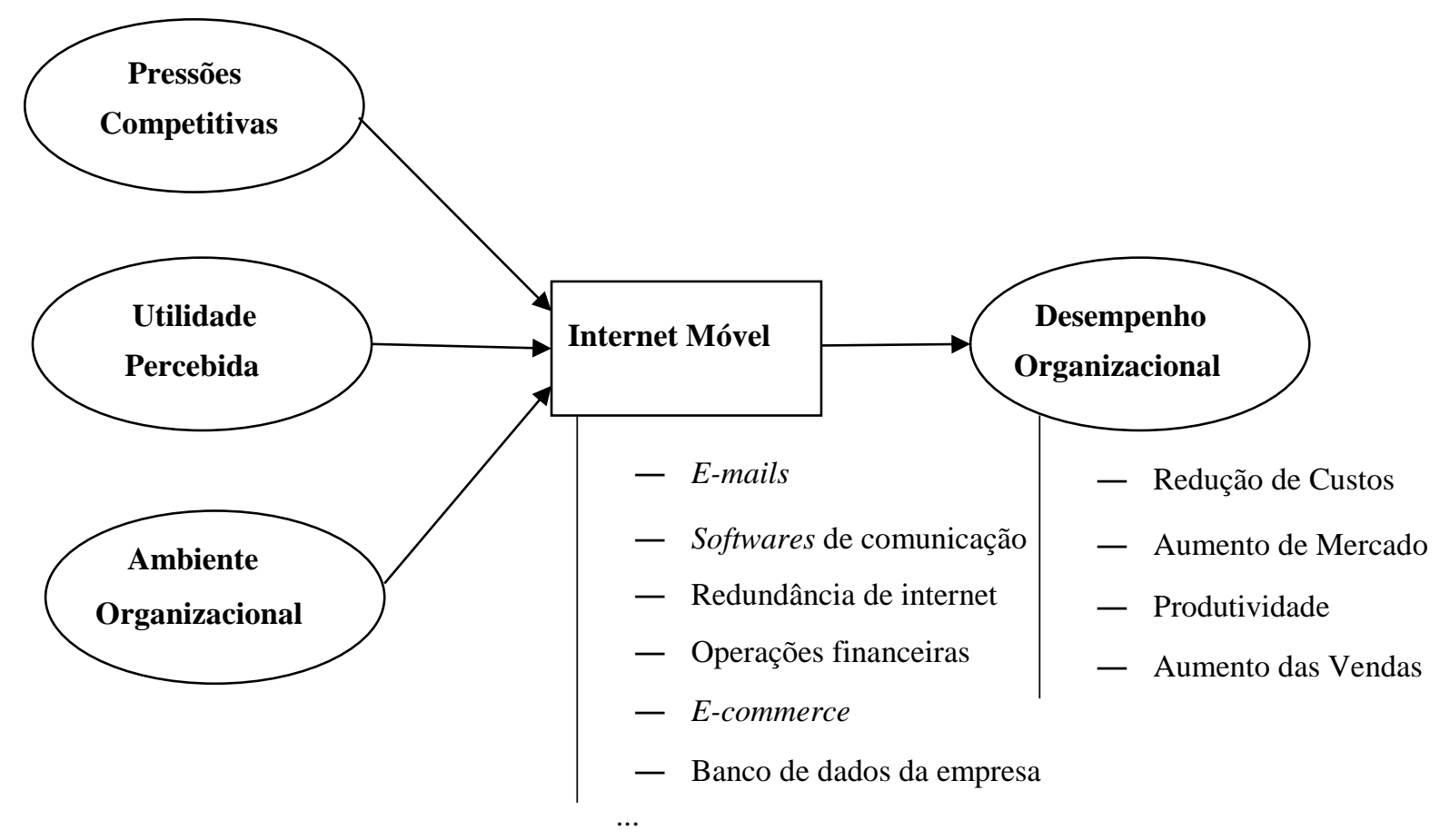

Figura 3. Modelo Ajustado de Pesquisa.

Com relação aos motivos que têm levado as empresas estudadas a adotarem a IM em seus negócios (Tabela 3 ), a utilidade percebida $(3,88)$ aparece como a principal razão. A percepção de que a Internet Móvel permite atender melhor as necessidades atuais da organização foi apontada como o principal motivo, seguido da possibilidade de realizar tarefas específicas mais rapidamente e da exigência da IM para o negócio da empresa. A adoção da IM permite aumentar a competitividade e a integração, emergindo como uma tendência forte para o uso das tecnologias móveis como meio para as empresas inovarem, aprimorarem a produtividade, melhorarem a integração e o marketing de relacionamento em relação ao tradicional conceito de atendimento de massa (Santos, 2007). Moore e Benbasat (1991) identificaram que a vantagem percebida de uma inovação está positivamente relacionada à sua taxa de adoção.

A presença de um ambiente organizacional adequado $(3,38)$ aparece como o segundo fator de adoção da Internet Móvel. Percebe-se que somente a intenção de se introduzir uma tecnologia como essa no dia a dia da empresa não é suficiente. A competência técnica para lidar com essa tecnologia é essencial para a sua adoção e principalmente para garantir o sucesso de seu uso (Kuan \& Chau, 2001). Similarmente, Cappellozza et al. (2011) evidenciam a infraestrutura de TI com relacionamento significante aos dispositivos móveis nas empresas do setor de serviços. Algumas barreiras técnicas, como locais sem acesso ou de difícil acesso à telefonia móvel, e a dificuldade do funcionário em se adaptar a tal tecnologia, podem decepcionar tanto o usuário quanto a alta administração da empresa, inclusive quanto aos resultados esperados com essa adoção. Como ocorre com qualquer outra tecnologia recente, há muitos fracassos de aplicações nas empresas que investiram nessa tecnologia (Turban et al., 2010). Ainda assim, a presença de ferramentas onde o usuário não precise realizar grande esforço em seu uso pode prevenir o problema de subutilização dessa tecnologia, seja apresentando uma plataforma amigável e de fácil aprendizado (Lin, 2011). 
Tabela 3

Motivos de Adoção - Análise Descritiva

\begin{tabular}{l|ccc}
\hline \multicolumn{1}{c|}{ Motivos de Adoção } & n & Média & Desvio-Padrão \\
\hline Utilidade Percebida & $\mathbf{9 6}$ & $\mathbf{3 , 8 8}$ & $\mathbf{0 , 8 5}$ \\
m10. Atender melhor as suas necessidades. & 96 & 4,16 & 0,84 \\
m3. Realizar tarefas específicas mais rapidamente. & 96 & 3,93 & 1,12 \\
m9. O seu negócio exigia. & 96 & 3,76 & 1,20 \\
m11. Aumentar a sua competitividade. & 96 & 3,68 & 1,24 \\
Ambiente Organizacional & $\mathbf{9 6}$ & $\mathbf{3 , 3 8}$ & $\mathbf{0 , 8 8}$ \\
m16. Possuía um ambiente favorável à sua utilização. & 96 & 3,72 & 1,07 \\
m12. Possuía uma estrutura organizacional adequada. & 95 & 3,47 & 1,09 \\
m8. Possuía funcionários com condições de utilizá-las. & 96 & 3,45 & 1,20 \\
m4. Possuía recursos financeiros. & 96 & 2,88 & 1,20 \\
Pressões Competitivas & $\mathbf{9 6}$ & $\mathbf{2 , 9 6}$ & $\mathbf{0 , 9 8}$ \\
m5. Em função do seu crescimento. & 96 & 3,56 & 1,20 \\
m1. Manter-se atualizada tecnologicamente. & 96 & 3,39 & 1,17 \\
m15. Para realizar suas atividades com maior segurança. & 96 & 3,06 & 1,27 \\
m2. Por causa da grande concorrência existente. & 96 & 2,91 & 1,34 \\
m14. Porque os concorrentes também têm adotado. & 96 & 2,47 & 1,18 \\
m6. Por influência dos clientes, fornecedores e/ou governo. & 95 & 2,47 & 1,25 \\
\hline
\end{tabular}

Já as pressões competitivas $(2,96)$ aparecem de forma menos intensa no caso da Internet Móvel. Talvez por ser uma tecnologia recente, ainda não tão madura, a questão de a concorrência estar utilizando ou a empresa sentir a necessidade de se atualizar tecnologicamente ainda não tem preocupado, ou pelo menos, impulsionado a adoção da IM, embora o crescimento orgânico da organização pareça exercer uma pequena pressão sobre utilizar a Internet Móvel como mais uma ferramenta operacional. As poucas empresas que vêm utilizando esta tecnologia são pioneiras ou líderes em seus setores, não sentindo pressões para adotar a IM. Como elas são as prospectoras, percebem outros fatores como mais importantes para a sua adoção. Santos (2007) defende que as mudanças que virão com o advento do $3 \mathrm{G}$ e Wimax, associadas a um perfil de consumidor mais exigente e cada vez mais habituado a buscar tudo na rede, sinalizam para a urgência de uma abordagem mais estratégica pelas empresas usuárias quanto à introdução de tecnologias móveis, embora se desconheça como serão projetadas as redes para atingirem tal objetivo.

No que se refere à percepção dos impactos do uso da IM sobre o desempenho organizacional (Tabela 4), o aumento da produtividade $(3,81)$ aparece como a principal consequência, em termos de benefícios organizacionais. Com menor intensidade, aparece que a Internet Móvel ajuda na obtenção de novos clientes $(3,26)$ e auxilia no aumento das receitas $(3,21)$. Por fim, ela impacta na redução dos custos operacionais $(3,13)$.

Nota-se que a adoção da Internet Móvel tem oportunizado às organizações, como principal benefício percebido, o aumento da produtividade. O uso da IM permite aos usuários não apenas verificar a disponibilidade de produtos, como também fazer pedidos de produtos em qualquer hora e local, quando estes se fizerem necessários. Para isto, basta ter acesso aos sistemas de informação corporativos através de algum dispositivo móvel. Essas soluções permitem que a empresa melhore o nível de serviço, faça ordens de serviço em tempo real e, com isso, reduza o tempo de processamento e entrega dessas ordens, o que oportuniza ganhos em termos de eficiência (Balloco et al., 2009). Sandi e 
Saccol (2010), ao investigarem a IM junto a equipes de vendas atuantes no Brasil, perceberam melhorias em diversos aspectos no desempenho comercial, como: no registro das informações comerciais (melhorou $80 \%$ ), monitoramento das atividades $(81,4 \%)$, atendimento das necessidades dos clientes $(90,7 \%)$, volume de vendas $(60 \%)$, número de atendimentos $(66,7 \%)$ e cumprimento de metas $(69,3 \%)$.

Tabela 4

\section{Desempenho Organizacional - Análise Descritiva}

\begin{tabular}{l|c|cc}
\multicolumn{1}{c|}{ Desempenho Organizacional } & n & Média & Desvio-Padrão \\
Aumenta a produtividade da empresa. & 96 & 3,81 & 1,06 \\
Ajuda na obtenção de novos clientes. & 96 & 3,26 & 1,20 \\
Auxilia no aumento das receitas. & 96 & 3,21 & 1,19 \\
Reduz os custos operacionais da empresa. & 95 & 3,13 & 1,26 \\
\hline
\end{tabular}

A possibilidade de concretizar negócios ou de prospectar novos clientes a partir da utilização da IM está mais associada ao acesso ou à mobilidade de o usuário poder realizar suas atividades, do que à geração de conteúdo que a IM lhe oportuniza quando este está fora do seu local de trabalho (especialmente quando se tratar de serviço de vendas) (Ghose \& Han, 2011). Segundo Gebauer e Shaw (2004), a adoção de uma solução móvel é direcionada pelo tempo que os seus usuários passam fora da empresa desempenhando suas atividades, sejam elas relacionadas às vendas ou a algum trabalho de campo.

A redução dos custos operacionais atribuída à adoção da IM foi percebida com menos intensidade pelos respondentes. Embora o principal motivador da adoção dessa tecnologia seja a sua utilidade percebida, conforme sugerido por Kim et al. (2007), o valor da IM é percebido pelos seus benefícios e estorvos, sendo o valor pago pelo desenvolvimento de aplicativos e pela utilização de dispositivos móveis uma importante questão a ser observada pelos gestores, ainda que estes custos venham baixando sistematicamente.

A análise descritiva permitiu identificar as principais aplicações corporativas da IM utilizadas pelas empresas investigadas, assim como sua frequência de uso (Tabela 5). Pode-se perceber que dentre os aplicativos de IM, enviar e receber e-mails é o mais comum (utilizado por $92,71 \%$ das empresas analisadas) e o mais frequentemente usado $(4,21)$. A possibilidade de ler, responder e se comunicar - ainda que de forma não instantânea - através de e-mails, sem estar à frente de um desktop, traz ganhos em termos de agilidade, conveniência, onipresença e até mesmo personalização (Turban et al., 2010). É válido observar que os serviços de mensagem, já em 2003, representavam o principal faturamento das empresas de telecomunicações em termos de aplicativos, representando $85 \%$ do uso, bem acima do acesso a conteúdos (10\%) e entretenimento (5\%) (Hsu, Lu, \& Hsu, 2007).

Tabela 5

\section{Principais Aplicativos Utilizados}

\section{Principais Aplicativos de Internet Móvel}

Enviar e receber $e$-mails.

Utilizar softwares de comunicação.

Redundância de Internet (caso saia do ar a internet fixa).

Acessar sites de bancos e realizar operações financeiras.

Realizar compras e vendas pela Internet (e-commerce).

Acessar remotamente o banco de dados da empresa. n

89

81

78

74

68

67

\section{$\%$}

92,71

84,37

81,25

77,08

70,83

69,79
Média

4,21

3,77

3,23

3,54

3,22

3,49 
Tabela 5 (continuação)

Principais Aplicativos de Internet Móvel

Acessar redes sociais (twitter, facebook).

Automatizar o serviço da equipe de vendas.

Automatizar o serviço da equipe técnica.

Monitorar alarmes e equipamentos de segurança.

Telemetria e controle da frota de veículos da empresa.

\begin{tabular}{ccc} 
n & \% & Média \\
\hline 66 & 68,75 & 3,58 \\
66 & 68,75 & 3,17 \\
56 & 58,33 & 3,50 \\
40 & 41,67 & 3,43 \\
20 & 20,83 & 3,20
\end{tabular}

n

20,83

3,20

Utilizar softwares de comunicação $(84,37 \%)$ e a Internet Móvel para redundância de Internet $(81,25 \%)$ vem logo a seguir, como outras aplicações bastante utilizadas. A aceleração da velocidade aparente da tecnologia de IM tem feito com que as pessoas optem por usar softwares de comunicação (messengers), além do e-mail. A conversação em tempo real é uma aproximação das relações e é extremamente conveniente também para a troca de informação com múltiplas pessoas (Pellanda, 2009). Por outro lado, o uso da IM, como forma de substituir a Internet fixa quando esta tem problemas, aponta para um benefício indireto dessa tecnologia, trazendo ganhos em termos de segurança e continuidade das atividades diárias, desde que seja possível se conectar a uma rede sem fio. A elevada utilização da IM para este fim aponta que a qualidade da conexão (definida pela conectividade e pela confiabilidade na rede) tem melhorado consideravelmente quando comparada há alguns anos atrás, especialmente porque esse tipo de conexão ainda oferece menor banda, menor estabilidade e previsibilidade do que a conexão tradicional (Gebauer, Shaw, \& Gribbins, 2010).

Já a telemetria ou o controle de frota de veículos $(20,83 \%)$ e o monitoramento de alarmes $(41,67 \%)$, por outro lado, foram as aplicações apontadas como as menos comuns. Serviços como esses, muito específicos, ainda não são utilizados em larga escala, porém indicam um grande potencial de se utilizar a Internet Móvel para apoio em serviços de localização, navegação, monitoramento, mapeamento e sincronização (Turban et al., 2010).

Balocco, Mogre e Toletti (2009), em pesquisa realizada com micro e pequenas empresas italianas, identificaram que 44,5\% das empresas analisadas utilizavam aplicativos de Internet Móvel para automatizar a equipe de vendas, $29 \%$ utilizavam a IM como um escritório móvel (capaz de enviar e receber e-mails, utilizar softwares de comunicação e acessar remotamente o banco de dados da empresa) e 26,5\% utilizavam aplicativos para automatizar a força de campo (auxiliando, dessa forma, o serviço da equipe técnica). Marques e João (2003), por sua vez, ao investigarem executivos de empresas de grande porte no ano de 2003, identificaram que, dentre os aplicativos de IM mais utilizados pelos executivos, o e-mail aparecia em primeiro lugar, sendo justificado por ser uma tecnologia madura e de fácil utilização. Em seguida, apareceu o acesso à intranet da empresa, recurso cada vez mais presente na rotina das organizações (o que permite acessar as informações corporativas de qualquer local e a qualquer momento). E, em terceiro lugar, apareceu o uso de diferentes aplicativos de forma remota, o que permite melhorar o desempenho dos gestores em termos de flexibilidade, produtividade e qualidade da tomada de decisão. É interessante ressaltar que, na época desse estudo, a telefonia celular disponibilizava uma taxa de transmissão de dados bem menos veloz do que as ofertadas atualmente.

Percebe-se que a adoção de tecnologias móveis pode criar dois tipos de impactos nas atividades organizacionais. A primeira é facilitar a comunicação entre funcionários, clientes e fornecedores. Através do aprimoramento da eficiência da comunicação e da rapidez na obtenção da informação, a IM pode aumentar a produtividade e a rentabilidade da empresa. A segunda é a possibilidade de modificar os processos de negócios através das mudanças dos padrões de acesso aos dados, o que permite a quem utiliza a IM oferecer serviços prontamente (Liang, Saraf, Hu, \& Xue, 2007). Ainda assim, pode ser visto que as aplicações de IM mais utilizadas são aquelas de natureza mais simples. As atividades envolvendo alguma modificação no processo de negócio (como acessar remotamente o banco de dados da empresa, automatizar o serviço da equipe de vendas ou o da equipe técnica) 
aparecem em outro grau de utilização, embora venham sendo usadas por mais da metade das empresas estudadas.

Diferentemente do que é colocado nos estudos gerais de gestão de TI, a aceitação do usuário e a necessidade de treinamento não são críticos quando se trata de soluções de IM (especialmente porque elas são muito semelhantes aos aplicativos utilizados na empresa e pelo usuário já estar familiarizado com as principais funcionalidades de seu dispositivo móvel), sendo as suas aplicações altamente aceitas pelos usuários quando estes entendem os seus benefícios (Balocco, Mogre, \& Toletti, 2009) e quando os aplicativos estão alinhados às tarefas dos usuários (Gebauer et al., 2010).

Apresentados os resultados referentes aos três primeiros objetivos desta pesquisa; procede-se aos resultados referentes ao quarto, e último, objetivo proposto: explorar possíveis associações entre fatores de adoção, aplicações e desempenho organizacional no contexto da IM. Para isso, desenvolveram-se três análises correlacionais usando o coeficiente de correlação de Pearson. Este mesmo coeficiente já foi utilizado em outros trabalhos da área de SI, buscando observar as relações existentes entre diferentes variáveis e a tecnologia de informação (Choe, 2005; Lunardi, Becker, \& Maçada, 2010).

Na primeira análise, exploram-se associações entre aplicações da Internet Móvel e fatores que influenciam a adoção na empresa. Os resultados podem sinalizar para cada aplicativo quais são os fatores que motivaram o seu uso na organização. Pôde-se constatar que, dos 11 aplicativos de Internet Móvel avaliados, somente cinco, destacados na Tabela 6, apresentaram correlação positiva significativa (ao nível de 5\%) com os motivos de adoção. Enviar e receber e-mails aparece fortemente correlacionado $(\mathrm{p}<0,01)$ com a utilidade percebida $(\mathrm{r}=0,528)$, mostrando que empresas que usam mais frequentemente a Internet Móvel para tal finalidade adotaram essa tecnologia, muito motivadas pela sua utilidade percebida. É bem verdade que os serviços de comunicação (Kim et al., 2007) associados à Internet Móvel permitem realizar atividades de forma mais ágil, o que consequentemente oportuniza ganhos de competitividade. Ainda assim, a concorrência e a estrutura da empresa também estão associadas ao uso do e-mail, porém com uma menor correlação $(\mathrm{r}=0,231$ e 0,217 , respectivamente).

Similarmente, encontra-se a aplicação de acessar bancos e realizar operações financeiras, porém, embora a correlação também seja mais forte com a utilidade percebida, novamente ocorre de forma não tão fraca $(r=0,392$ e $r=0,316)$ com os outros dois fatores de adoção, todas significativas $(\mathrm{p}<0,01)$. Tais correlações moderadas podem indicar que este uso começa a se tornar comum nas empresas, derivando uma pressão externa, assim como que o uso da IM nesta aplicação exige determinadas condições estruturais internas à empresa.

Tabela 6

Coeficientes de Correlação de Pearson entre o Uso de Aplicativos de Internet Móvel e os Fatores de Adoção

\begin{tabular}{|c|c|c|}
\hline $\begin{array}{c}\text { Ambiente } \\
\text { Organizacional }\end{array}$ & $\begin{array}{l}\text { Utilidade } \\
\text { Percebida }\end{array}$ & $\begin{array}{c}\text { Pressões } \\
\text { Competitivas }\end{array}$ \\
\hline ,217(*) &, $528(* *)$ & ,231(*) \\
\hline ,035 & ,239(*) & ,138 \\
\hline ,316(**) &, $505(* *)$ & ,392(**) \\
\hline 091 & ,242 &, $304(*)$ \\
\hline ,014 &, $237(*)$ &, $233\left({ }^{*}\right)$ \\
\hline
\end{tabular}

Nota. ** Correlação significativa ao nível de 0,01 ; * Correlação significativa ao nível de 0,05

Quanto aos outros três aplicativos, cujas correlações se mostraram significativas (porém não tão expressivas), percebe-se que a possibilidade de realizar compras e vendas pela internet através da 
Internet Móvel (chamado de M-Commerce) sofre uma interferência do mercado, apresentando correlação moderada com pressões competitivas, uma vez que um número cada vez maior de empresas tem permitido a realização de compras e vendas dessa forma. $\mathrm{O}$ uso da telemetria mostra-se associado à sua utilidade percebida, possibilitando resolver problemas específicos, porém também se associa a pressões competitivas, provavelmente relacionadas à influência de seus fornecedores de equipamentos. Já o uso da redundância de Internet, que visa garantir o acesso à rede quando o dispositivo similar com fio tiver problemas, associa-se exclusivamente à utilidade percebida.

Na sequência, procedeu-se à segunda análise, visando explorar associações entre desempenho organizacional e aplicações da IM (Tabela 7). Os resultados podem indicar aplicações que trazem retorno econômico às empresas. Nesse sentido, o aplicativo para automatizar o serviço da equipe de vendas destaca-se dos demais, pois apresenta as correlações mais fortes com três das quatro variáveis analisadas sobre o desempenho organizacional, a saber: aumenta a produtividade da empresa $(\mathrm{r}=$ $0,330)$, ajuda na obtenção de novos clientes $(r=0,398)$ e auxilia no aumento das receitas $(r=$ 0,298). O uso da IM abre novas oportunidades de negócios, amplia o seu alcance e possibilita oferecer serviços prontamente (Balocco et al., 2009; Liang et al., 2007; San Martín et al., 2012), aumentando o potencial da equipe de vendas para gerar negócios de forma mais produtiva. No que se refere à quarta variável, reduz os custos operacionais da empresa, a correlação mais intensa é com a aplicação troca de $\boldsymbol{e}$-mails $(\mathrm{r}=0,376)$, intimamente relacionada à minimização de deslocamentos e ao uso de outros meios de comunicação mais dispendiosos.

Tabela 7

Coeficientes de Correlação de Pearson entre Desempenho Organizacional e Aplicações

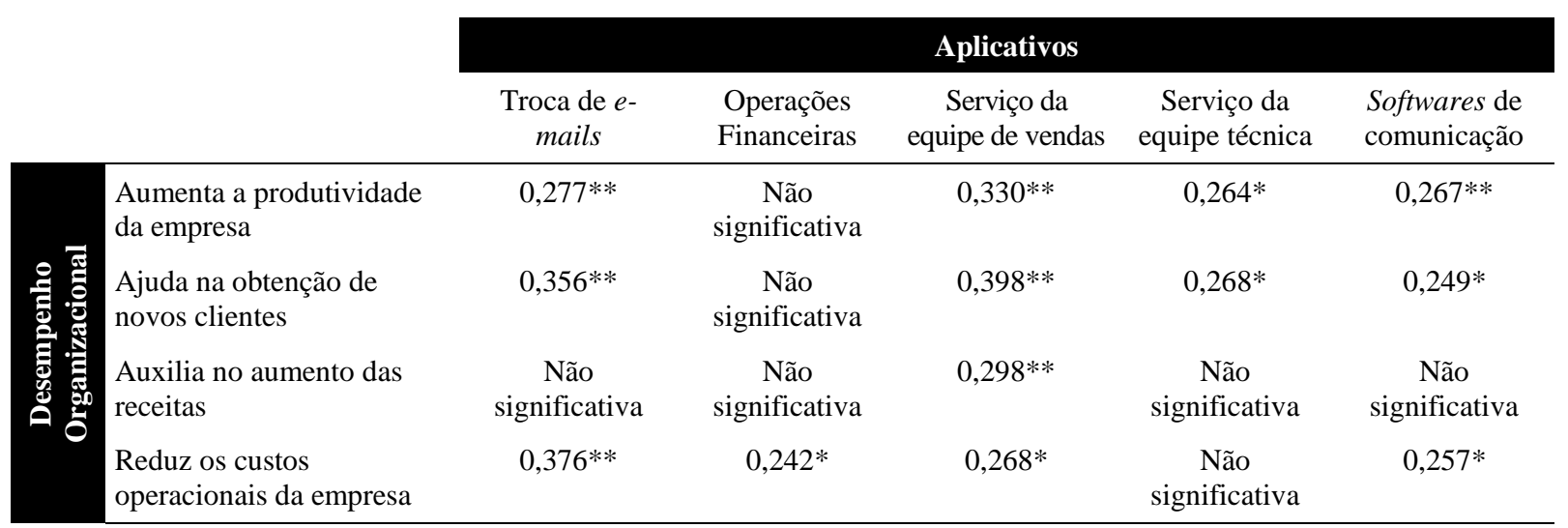

Nota. ** Correlação significativa ao nível de 0,01 ; * Correlação significativa ao nível de 0,05.

De modo a facilitar a visibilidade dos resultados das análises correlacionais realizadas até aqui, apresentam-se na Figura 4 os índices de correlação, resultantes das associações estatisticamente significativas. É válido destacar que apenas duas aplicações da IM - e-mail e operações financeiras apresentaram relações significativas com os fatores de Adoção e com as medidas de desempenho organizacional. 


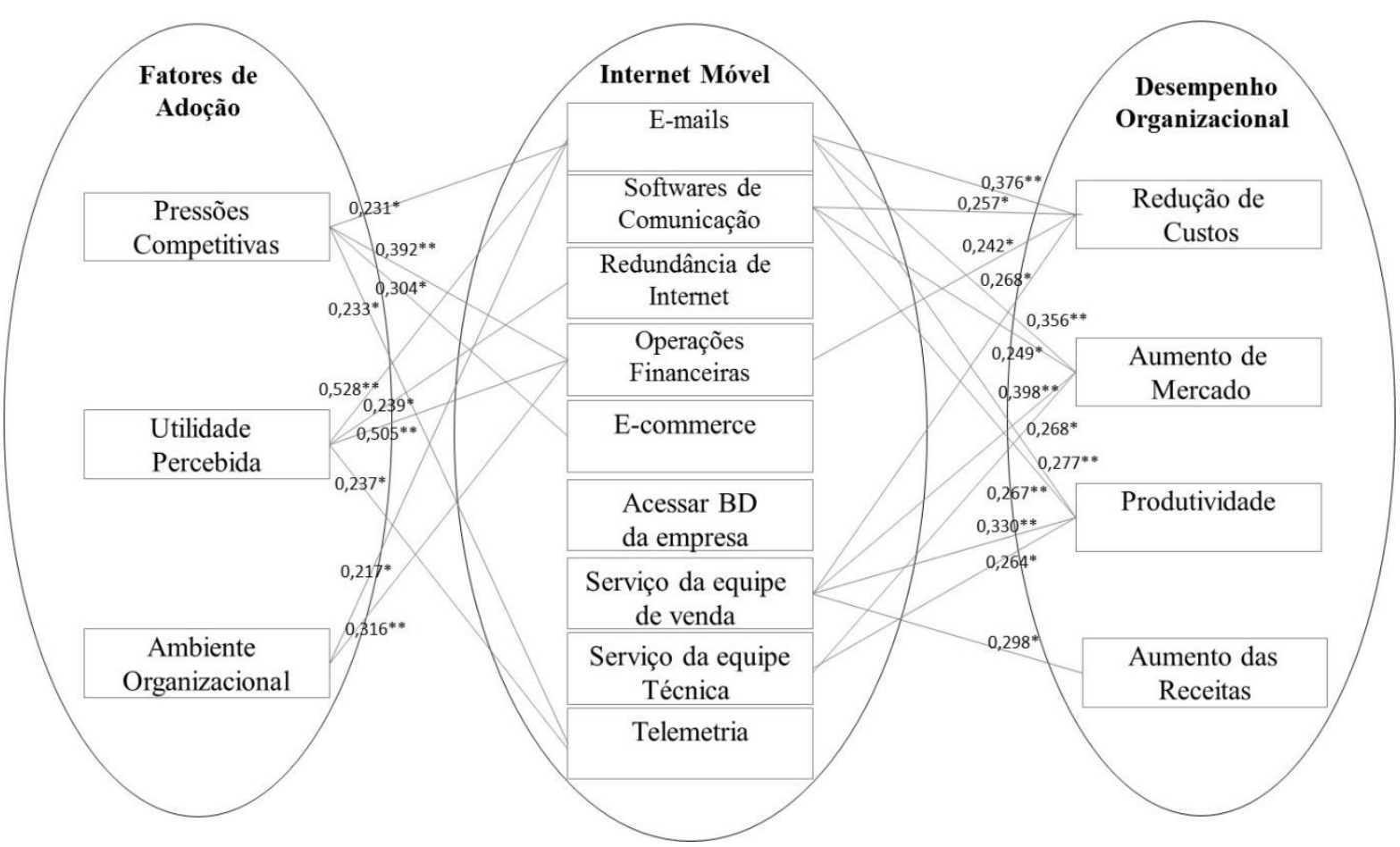

Figura 4. Modelo Ajustado de Pesquisa - Relações Significativas.

** Correlação significativa ao nível de 0,01 - * Correlação significativa ao nível de 0,05 .

Por fim, analisaram-se correlações entre as variáveis de desempenho e os fatores de adoção (Tabela 8). Os resultados presentes em Lunardi, Dolci et al. (2010) instigaram tal análise. Os autores, explorando o relacionamento entre a adoção da TI e seu impacto percebido no desempenho das micro e pequenas empresas, concluem que fatores de adoção, como as pressões externas e o ambiente organizacional, afetam o desempenho organizacional. Surge, então, a curiosidade: Que associações se estabelecem no contexto da IM?

Tabela 8

Coeficientes de Correlação de Pearson entre Desempenho Organizacional e Fatores de Adoção

\begin{tabular}{ccc}
\hline & Fatores de Adoção & \\
\hline $\begin{array}{c}\text { Pressões } \\
\text { Competitivas }\end{array}$ & $\begin{array}{c}\text { Utilidade } \\
\text { Percebida }\end{array}$ & $\begin{array}{c}\text { Ambiente } \\
\text { Organizacional }\end{array}$ \\
\hline $0,416^{* *}$ & $0,506^{* *}$ & $0,501^{* *}$ \\
$0,508^{* *}$ & $0,575^{* *}$ & $0,550^{*}$ \\
$0,521^{* *}$ & $0,536^{* *}$ & $0,527^{* *}$ \\
$0,542^{* *}$ & $0,586^{* *}$ & $0,465^{* *}$ \\
\hline
\end{tabular}

Nota. ** Correlação significativa ao nível de 0,$01 ; *$ Correlação significativa ao nível de 0,05 .

Nesta análise (Tabela 8), as correlações, além de positivas e significativas, mostraram-se mais fortes do que nas análises anteriores. A grande maioria acima de 0,50 . A utilidade percebida é a variável que apresenta correlações mais fortes com todas as variáveis de desempenho organizacional aumenta a produtividade da empresa $(r=0,506)$, ajuda na obtenção de novos clientes $(r=0,575)$, auxilia no aumento das receitas $(r=0,536)$, reduz os custos operacionais da empresa $(r=0,586)$. Ao se observarem os conjuntos de análises correlacionais (Tabelas 6, 7 e 8), percebe-se que o conjunto das correlações entre as variáveis de desempenho organizacional e de Fatores de Adoção (Tabela 8) 
destaca-se pela ausência de relações não significativas e por apresentar uma porcentagem elevada de correlações acima de 0,50, diferente do presente nos demais conjuntos. Uma possível interpretação para esse conjunto com correlações mais fortes, diferenciando-se das demais, é que os fatores de adoção da TI realmente assumem um importante papel no impacto produzido no desempenho organizacional, corroborando com os achados de Lunardi, Dolci et al. (2010).

\section{Considerações Finais}

Este estudo traz importantes contribuições para a área de SI. Os trabalhos realizados sobre IM têm seu auge a partir de 2007, porém poucas pesquisas têm abordado a sua adoção nas empresas. A fim de contribuir para o tema, traçou-se a presente investigação com o objetivo de identificar os principais motivos que têm levado as organizações a adotar a IM, além de identificar os efeitos percebidos do seu uso no desempenho organizacional. A análise empírica trouxe uma série de implicações teóricas e práticas. Teoricamente, disponibiliza-se um modelo capaz de entender os principais determinantes da adoção da IM pelas empresas e seu impacto no desempenho organizacional percebido. Em uma perspectiva gerencial, os achados aqui obtidos podem oferecer insights aos gestores quanto ao entendimento e ao uso da IM quando direcionada ao uso corporativo, seja dando suporte às atividades individuais ou ainda à coordenação e ao gerenciamento do trabalho de forma distribuída.

Identificou-se que, dentre os aplicativos de IM, enviar e receber $\boldsymbol{e}$-mails é o mais comum e o mais frequentemente usado. Já o uso de softwares de comunicação e da Internet Móvel para redundância de Internet aparecem como outros aplicativos de grande utilização. Os resultados do estudo sugerem que a adoção da IM é influenciada pela utilidade percebida, ambiente organizacional e pressões competitivas, sendo a utilidade percebida o principal motivador. A percepção de que a IM permite atender melhor as necessidades atuais da organização foi apontada pelas empresas pesquisadas como o principal motivo de adoção, seguido da possibilidade de realizar tarefas específicas mais rapidamente e da exigência do negócio. Ainda assim, a necessidade de apresentar um ambiente organizacional favorável à utilização da IM, com uma estrutura organizacional adequada e com funcionários capazes de utilizá-la também são levadas em consideração ao se adotar a IM.

Com relação aos efeitos percebidos do uso da IM no desempenho organizacional, constatou-se que a IM aumenta principalmente a produtividade da empresa, sendo este efeito seguido pela obtenção de novos clientes, aumento das receitas e, por fim, redução dos custos operacionais. A IM facilita a comunicação entre funcionários, clientes e fornecedores (seja pela eficiência da comunicação ou pela rapidez na obtenção da informação), além de permitir modificações nos processos de negócio da empresa. Por fim, encontraram-se algumas associações entre as aplicações de IM, os motivos de adoção e o impacto do seu uso no desempenho organizacional. Destacam-se as funcionalidades de enviar e receber $e$-mails, acessar e realizar operações financeiras, usar a Internet Móvel como redundância da Internet fixa e a telemetria e controle de frota de veículos entre as aplicações que apresentam pelo menos uma associação significativa com os fatores de adoção. Embora o uso de aplicativos da IM específicos para realizar serviços da equipe de vendas seja a aplicação mais intensamente associada ao desempenho organizacional, os motivos de adoção relacionados à utilidade percebida e ao ambiente organizacional estão mais fortemente associados às medidas de desempenho organizacional, evidenciando o quanto a forma de adoção é importante para o sucesso da tecnologia na organização.

Como principais limitações do estudo, aponta-se a seleção da amostra, reduzindo-a a um grupo variado de empresas localizadas em uma região específica do Brasil, em sua grande maioria, micro e pequenas empresas. Ressalta-se, também, a amplitude do período de coleta de dados (cerca de seis meses), que pode interferir na exatidão das análises, dada a natureza dinâmica de estudos da área de SI. Tais limitações sugerem cuidados na interpretação dos resultados obtidos, descartando 
generalizações. Ainda assim, acredita-se que os resultados possam auxiliar tanto os executivos a planejar a adoção da IM em suas empresas como também os pesquisadores interessados nesta temática. Como estudos futuros, sugere-se a realização de uma pesquisa contemplando o estado-daarte da literatura sobre o tema IM nas organizações brasileiras. Recomenda-se, ainda, a aplicação do instrumento de pesquisa desenvolvido em outros contextos, de modo a verificar a sua validade externa e apresentar estudos comparativos; e, por fim, o aperfeiçoamento dos modelos de mensuração e o desenvolvimento de modelos teóricos fundamentando diferentes relações causais. Nesse sentido, podese avaliar possíveis relações de causa e efeito entre os fatores de adoção da IM e o desempenho organizacional, analisando efeitos diretos e indiretos.

\section{Referências}

Agência Nacional de Telecomunicações. (2012). Em março, telefonia móvel ultrapassa 250 milhões de linhas ativas. Recuperado de http://www.anatel.gov.br/Portal/exibirPortalNoticias.do?acao=carregaNoticia\&codigo $=2516$

Amato, F. (2012, abril 3). Plano deve antecipar R $\$ 18$ bilhões de investimento em banda larga. G1. Globo.com. Recuperado de http://g1.globo.com/tecnologia/noticia/2012/04/plano-deveantecipar-r-18-bilhoes-de-investimento-em-banda-larga.html

Balocco, R., Mogre, R., \& Toletti, G. (2009). Mobile internet and SMEs: a focus on the adoption. Industrial Management \& Data Systems, 109(2), 245-261. doi: http://dx.doi.org/10.1108/02635570910930127

Barbetta, P. (1998). Estatística aplicada às ciências sociais. Florianópolis: Editora da UFSC.

Bento, F., Martens, C., \& Freitas, H. (2013). Proposição de elementos decorrentes da adoção de tecnologias móveis em equipes comerciais. Anais do Encontro de Administração da Informação, Bento Gonçalves, RS, Brasil, 4.

Bojnec, Š., \& Ferto, I. (2012). Broadband availability and economic growth. Industrial Management \& Data Systems, 112(9), 1292-1306. doi: 10.1108/02635571211278938

Cappellozza, A., Sanchez, O., \& Albertin, A. (2011, maio). Estudo da influência da infraestrutura de tecnologia de informação à mobilidade computacional dos usuários e utilização da computação em nuvem, aplicado em empresas do setor de serviços. Anais do Encontro de Administração da Informação, Porto Alegre, RS, Brasil, 3.

Cavazotte, F., Brollo, M., \& Moreno, V. (2009, setembro). Mobilidade computacional no trabalho: um estudo sobre as experiências dos usuários de telefones inteligentes. Anais do Encontro Nacional da Associação Nacional de Pós-Graduação e Pesquisa em Administração, São Paulo, SP, Brasil, 33.

Chae, M., \& Kim, J. (2003).What's so different about the mobile internet? Communications of the ACM, 46(12), 240-247. doi: 10.1145/953460.953506

Chaves, S., Veríssimo, H., Silva, A., Souza, J. B., \& Cotti, P. (2010). Adoção da internet móvel para uso pessoal. Proceedings of the AMCIS. Recuperado de http://aisel.aisnet.org/amcis2010/195

Chen, L., \& Nath, R. (2008). A socio-technical perspective of mobile work. Information Knowledge Systems Management, 7(1/2), 41-60.

Choe, J. (2005). The relationships among management accounting information, organizational learning and production performance. Journal of Strategic Information Systems, 13(1), 61-85. doi: $10.1016 /$ j.jsis.2004.01.001. 
Corso, K., Cavedon, N., \& Freitas, H. (2011, maio). Mobilidade espacial, temporal e contextual: um estudo de inspiração etnográfica sobre o trabalho móvel em shopping center. Anais do Encontro de Administração da Informação, Porto Alegre, RS, Brasil, 3.

Corso, K., Freitas, H., \& Behr, A. (2012, setembro). Os paradoxos de uso da tecnologia de informação móvel: a percepção de docentes usuários de smartphones. Anais do Encontro Nacional da Associação Nacional de Pós-Graduação e Pesquisa em Administração, Rio de Janeiro, RJ, Brasil, 36.

Costa, E., Saccol, A., \& Vieira, L. (2011, setembro). Análise da utilização de tecnologias da informação móveis e sem fio (TIMS) na cadeia bovina: um estudo de caso no Estado de Goiás. Anais do Encontro Nacional da Associação Nacional de Pós-Graduação e Pesquisa em Administração, Rio de Janeiro, RJ, Brasil, 35.

Cragg, P., \& King, M. (1993). Small-firm computing: motivators and inhibitors. MIS Quarterly, 17(1) 47-60. doi: $10.2307 / 249509$

Davis, F. (1989). Perceived usefulness, perceived ease of use, and user acceptance of information technology. MIS Quarterly, 13(3) 319-340. doi: 10.2307/249008

Gebauer, J., \& Shaw, M. J. (2004). Success factors and impacts of mobile business applications: results from a mobile e-procurement study. International Journal of Electronic Commerce, 8(3), $19-41$.

Gebauer, J., Shaw, M. J., \& Gribbins, M. (2010). Task-technology fit for mobile information systems. Journal of Information Technology, 25(3), 259-272. doi: 10.1057/jit.2010.10

Ghose, A., \& Han, S. (2011). An empirical analysis of user content generation and usage behavior on the mobile Internet. Management Science, 57(9), 1671-1691. doi: 10.1287/mnsc.1110.1350

Gonçalves, A., \& Joia, L. (2011, setembro). Uma investigação acerca dos paradoxos presentes na relação entre executivos e smartphones. Anais do Encontro Nacional da Associação Nacional de Pós-Graduação e Pesquisa em Administração, Rio de Janeiro, RJ, Brasil, 35.

Grandon, E., \& Pearson, J. (2004). Electronic commerce adoption: an empirical study of small and medium US businesses. Information \& management, 42(1), 197-216. doi: 10.1016/j.im.2003.12.010

Grant, R. (2003). Strategic planning in a turbulent environment: evidence from the oil majors. Strategic Management Journal, 24(6), 491-517. doi: 10.1002/smj.314

Hair, J., Black, W., Babin, B., Anderson, R., \& Tatham, R. (2005). Análise multivariada de dados. Porto Alegre: Bookman.

Hong, S., Thong, J., \& Tam, K. (2006). Understanding continued information technology usage behavior: a comparison of three models in the context of mobile internet. Decision Support Systems, 42(3), 1819-1834. doi: 10.1016/j.dss.2006.03.009

Hsu, C., Lu, H., \& Hsu, H. (2007). Adoption of the mobile internet: an empirical study of multimedia message service. Omega, 35(6), 715-726. doi: 10.1016/j.omega.2006.03.005

Hsu, C., Wang, C., \& Lin, J. (2011). Investigating customer adoption behaviours in mobile financial services. International Journal of Mobile Communications, 9(5), 477-494. doi: 10.1007/s00779006-0120-5

Hu, Q., \& Plant, R. (2001). An empirical study of the casual relationship between IT investment and firm performance. Information Resources Management Journal, 14(3), 15-26. doi: 10.4018/irmj.2001070102 
Idgnow. (2012, abril 25). Tablets dominarão mercado em quatro anos, aponta estudo. Recuperado de http://idgnow.uol.com.br/mobilidade/2012/04/24/tablets-dominarao-mercado-em-quatro-anosaponta-estudo/\#\&panel2-1

Idgnow. (2013, março 14). Brasil registrou 30 smartphones vendidos por minuto em 2012, diz IDC. Recuperado de http://idgnow.uol.com.br/mobilidade/2013/03/14/venda-de-smartphones-cresce78-no-brasil-em-2012-diz-ide/

Info. (2012, abril 22). Brasil é o quinto país mais conectado do mundo. Recuperado de http://info.abril.com.br/noticias/internet/brasil-e-o-quinto-pais-mais-conectado-do-mundo22042012-7.shl?utm_source=feedburner\&utm_medium=feed\&utm_campaign=Feed\%3A+ NoticiasINFO-Internet+\%28Not\%C3\%ADcias+INFO+-+Internet\%29

Jarvenpaa, S., \& Lang, K. (2005). Managing the paradoxes of mobile technology. Information Systems Management, 22(4), 7-23. doi: 10.1201/1078.10580530/45520.22.4.20050901

Khalifa, M., \& Shen, K. (2008). Explaining the adoption of transactional B2C mobile commerce. Journal of Enterprise Information Management, 21(2), 110-124. doi: $10.1108 / 17410390810851372$

Kim, H., Chan, H., \& Gupta, S. (2007). Value-based adoption of mobile internet: an empirical investigation. Decision Support Systems, 43(1), 111-126. doi: 10.1016/j.dss.2005.05.009

Klein, A., Karl, F., \& Cunha, M. (2013, setembro). A capacidade organizacional para a mobilidade e seus componentes. Anais do Encontro Nacional da Associação Nacional de Pós-Graduação e Pesquisa em Administração, Rio de Janeiro, RJ, Brasil, 37.

Kolko, J. (2012). Broadband and local growth. Journal of Urban Economics, 71(1), 100-113. doi: 10.1016/j.jue.2011.07.004

Kuan, K., \& Chau, P. (2001). A perception-based model for EDI adoption in small businesses using a technology-organization-environment framework. Information \& Management, 38(8), 507-521. doi: 10.1016/S0378-7206(01)00073-8

Laudon, K., \& Laudon, P. (2010). Sistemas de informações gerenciais. São Paulo: Pearson Prentice Hall.

Liang, H., Saraf, N., Hu, Q., \& Xue, Y. (2007). Assimilation of enterprise systems: the effect of institutional pressures and the mediating role of top management. MIS Quarterly, 31(1), 59-87.

Lin, H. (2011). An empirical investigation of mobile banking adoption: the effect of innovation attributes and knowledge-based trust. International Journal of Information Management, 31(3), 252-260. doi: 10.1016/j.ijinfomgt.2010.07.006

Lunardi, G., Becker, J., \& Maçada, A. (2010). Impacto da adoção de mecanismos de governança de tecnologia de informação (TI) no desempenho da gestão da TI: uma análise baseada na percepção dos executivos. Revista de Ciências da Administração, 12(28), 11-39. doi: $10.5007 / 2175-8077.2010 \mathrm{v} 12 \mathrm{n} 28 \mathrm{p} 11$

Lunardi, G., Dolci, P., \& Maçada, A. (2010). Adoção de tecnologia de informação e seu impacto no desempenho organizacional: um estudo realizado com micro e pequenas empresas. Revista de Administração, 45(1) 5-17.

Machado, C., \& Freitas, H. (2007, outubro). Modelo para planejamento de iniciativas de adoção de tecnologias móveis na interação entre organização e indivíduo. Anais do Encontro de Administração da Informação, Florianópolis, SC, Brasil, 1. 
Manica, A., \& Saccol, A. (2009, setembro). Avaliação dos resultados de adoção de tecnologias da informação móveis e sem fio (TIMS): o caso do IBGE - censo 2007. Anais do Encontro Nacional da Associação Nacional de Pós-Graduação e Pesquisa em Administração, São Paulo, SP, Brasil, 33.

Marques, E., \& João, B. (2003, setembro). Mobilidade: uma investigação de uso por executivos brasileiros. Anais do Encontro Nacional da Associação Nacional de Pós-Graduação e Pesquisa em Administração, Atibaia, SP, Brasil, 27.

Melville, N., Kraemer, K., \& Gurbaxani, V. (2004). Review: information technology and organizational performance: an integrative model of IT business value. MIS quarterly, 28(2), 283-322.

Moore, G., \& Benbasat, I. (1991). Development of an instrument to measure the perceptions of adopting an information technology innovation. Information systems research, 2(3), 192-222. doi: $10.1287 /$ isre.2.3.192

Orlikowski, W. J. (2000). Using technology and constituting structures: a practice lens for studying technology in organizations. Organization Science, 11(4), 404-428. doi: 10.1287/orsc.11.4.404.14600

Pavlou, P., \& El Sawy, O. (2010). The "third hand": IT-enabled competitive advantage in turbulence through improvisational capabilities. Information Systems Research, 21(3), 443-471. doi: 10.1287/isre. 1100.0280

Pellanda, E. (2009). Comunicação móvel: das potencialidades aos usos e aplicações. Em questão, 15(1), 89-98.

Prates, G., \& Ospina, M. (2004). Tecnologia da informação em pequenas empresas: fatores de êxito, restrições e benefícios. Revista de Administração Contemporânea, 8(2), 9-26. doi: 10.1590/S1415-65552004000200002

Reuver, M., Ongena, G., \& Bouwman, H. (2013). Should mobile Internet be an extension to the fixed web? Fixed-mobile reinforcement as mediator between context of use and future use. Telematics and Informatics, 30(2), 111-120. doi: 10.1016/j.tele.2012.02.002

Rose, G., \& Straub, D. (1998). Predicting general IT use: applying TAM to the Arabic world. Journal of Global Information Management, 6(3), 39-46. doi: 10.4018/jgim.1998070104

Saccol, A., \& Reinhard, N. (2005, setembro). Processo de adoção e decorrências da utilização de tecnologias de informação móveis e sem fio no contexto organizacional. Anais do Encontro Nacional da Associação Nacional de Pós-Graduação e Pesquisa em Administração, Brasília, Brasil, 29.

Saccol, A., \& Reinhard, N. (2007). Tecnologias de informação móveis, sem fio e ubíquas: definiçőes, estado-da-arte e oportunidades de pesquisa. Revista de Administração Contemporânea, 11(4), 175-198. doi: 10.1590/S1415-65552007000400009

Sandi, L., \& Saccol, A. (2010) Sobrecarga de informações geradas pela adoção de tecnologias da informação móveis e sem fio e suas decorrências para profissionais de vendas. Revista Eletrônica de Sistemas de Informação, 9(2). Recuperado de http://revistas.facecla.com.br/index.php/reinfo/article/download/781/pdf_2. doi: 10.5329/RESI.2010.0902002

San Martín, S., López-Catalán, B., \& Ramón-Jerónimo, M. (2012). Factors determining firms' perceived performance of mobile commerce. Industrial Management \& Data Systems, 112(6), 946-963. doi: 10.1108/02635571211238536 
Santos, J. (2007). Demanda latente e implicações da internet banda larga móvel nas empresas (Tese de doutorado). Universidade Federal de Santa Catarina, Florianópolis, SC, Brasil. Recuperado de http://repositorio.ufsc.br/xmlui/handle/123456789/90408

Shankar, V., Venkatesh, A., Hofacker, C., \& Naik, P. (2010). Mobile marketing in the retailing environment: current insights and future research avenues. Journal of Interactive Marketing, 24(2), 111-120. doi: 10.1016/j.intmar.2010.02.006

Souza, R., Ferreira, J., Hor-Meyll, L., Silva, J., \& Giovannini, C. (2012, maio). Aceitação da internet móvel pelo consumidor. Anais do Encontro da Divisão de Marketing, Curitiba, PR, Brasil, 5.

Tavares, E., Lucas, C., Dialo, M., Leo, P., Monnoyer, M., \& Philippe, J. (2012, setembro). A influência do uso de tecnologias móveis na inovação em serviços. Anais do Encontro Nacional da Associação Nacional de Pós-Graduação e Pesquisa em Administração, Rio de Janeiro, RJ, Brasil, 36.

Thompson, H., \& Garbacz, C. (2011). Economic impacts of mobile versus fixed broadband. Telecommunications Policy, 35(11), 999-1009. doi: 10.1016/j.telpol.2011.07.004

Turban, E., Leidner, D., McLean, E., \& Wetherbe, J. (2010). Tecnologia da informação para gestão. Porto Alegre: Bookman.

Ungan, M. (2004). Factors affecting the adoption of manufacturing best practices. Benchmarking: an International Journal, 11(5), 504-520. doi: 10.1108/14635770410557726

Wang, Y., Wang, Y., \& Yang, Y. (2010). Understanding the determinants of RFID adoption in the manufacturing industry. Technological Forecasting and Social Change, 77(5), 803-815. doi: http://dx.doi.org/10.1016/j.techfore.2010.03.006

Zhang, L., Zhu, J., \& Liu, Q. (2012). A meta-analysis of mobile commerce adoption and the moderating effect of culture. Computers in Human Behavior, 28(5), 1902-1911. doi: 10.1016/j.chb.2012.05.008 